\title{
Biological Activity and Field Persistence of Pelargonium graveolens (Geraniales: Geraniaceae) loaded Solid Lipid Nanoparticles (SLNs) on Phthorimaea operculella (Zeller) (PTM) (Lepidoptera: Gelechiidae)
}

\author{
Adel, M.M. ${ }^{1}$, Atwa, W.A ${ }^{2}$, Hassan, M.L. ${ }^{3}$, Salem, N.Y ${ }^{4}$, Farghaly, D.S ${ }^{5}$, Ibrahim, S.S ${ }^{6}$ \\ ${ }^{1,3,4,6}$ National Research Centre, Cairo, EGYPT \\ ${ }^{2,5}$ Faculty of Science, Al-Azhar University, Cairo, EGYPT
}

\begin{abstract}
A new delivery system (was used) to control the potato tuber larvae Phthorimaea operculella (Zeller) (PTM) (Lepidoptera: Gelechiidae) based on incorporation of geranium essential oil into solid lipid nanoparticles (SLNs) was prepared using ultrasonicsolvent emulsification technique. EO-SLNs were characterized using Transmission Electron Microscopy (TEM). The results were compared with geranium essential bulk and post loading solid lipid nanoparticles tested in the laboratory and field for their efficiency on larval development, pupal mortality and adult longevity. Laboratory bioassay indicated that geranium essential oil loaded nanoparticles was more effective on both larval and pupal development as well as the adult longevity and female fecundity accordingly the percentage of hatchability. Field-laboratory experiments were conducted to show direct and residual effects of the tested oil free and post loading against the first larval instar of the pest in terms of toxicity and stability. The results indicated that geranium essential oil loaded solid lipid nanoparticles was stable under field conditions and give high percentage of mortality at the two concentrations used. Data presented in this work show greater efficiency of geranium essential oil nanoparticles in controlling Ph. operculella in field.
\end{abstract}

Keywords: geranium essential oil nanoparticles, EO-SLNs, Phthorimaea operculella, Nanoformulation

\section{Introduction}

The potato tuber moth, Phthorimaea operculella (Zeller) (PTM) (Lepidoptera: Gelechiidae) is considered as one of the most destructive insect pests of cultivated potato in the field and storage, infection in the storage caused by transporting the tubers infested with insects. In developing countries usually synthetic insecticides are used to control insect pests and the extensive use of these chemical insecticides leads to severe risks to human health and the environment, it reduced the populations of natural enemies and developed the insect resistance to synthetic insecticides (Llanderal-Cazares et al., 1996). There is an urgent need to find safe and effective alternatives to these chemical insecticides. Plant oils could be an alternative and used as biopesticide, it could occupy a predominant role in the integrated pest management approach (Sharaby et. al., 2009). These active substances extracted from plants are effective against wide range of insect pests (Al-Dhafer, 2001; Lee et al., 2004; Al-Dosary, 2007), and could act as toxicants, as insect growth regulators, as repellents or as phagodeterrents (Burfield and Reekie, 2005).

It was reported that the potato tuber moth, Ph. operculella infestation can be reduced in storage when potatoes are intermixed with garlic bits, Allium sativum L. (Garlic: Liliaceae) and dried neem leaves (Siddig, 1986).Rama (1989) reported that some active oils extracted from different plants of different families acted as ovicidal and larvicidal against the $P h$. operculella. Kroscheland Koch (1996) found that the treatment with extracts of garlic and the fruits of the neem-related chinaberry resulted in fewer larvae of $P h$. operculella developing to the adult stage than in the control. The bioactivities of marjoram essential oil against immature stages and adults of PTM Ph. operculella were examined by Abd El-Aziz (2011) and it was found that the essential oil showed significant contact and fumigation insecticidal activities against different stages of the pest However, the major inconvenience of the use of essential oils is their chemical instability in the presence of air, light, moisture, and high temperatures that can determine the rapid evaporation and degradation of some active components (Regnault-Roger et. al., 2012). A method to overcome these problems is the incorporation of essential oils into a controlled-release nanoformulation which prevents rapid evaporation and degradation; enhances stability and maintains the minimum effective dosage/application (Ghormade et al., 2011). In addition, this nanoformulation compared with bulk formulations is expected to be more effective, showed less toxicity towards non-target organisms, reduced using and less amount of pesticides applied, and increased persistence of the active ingredient (Anjali et al., 2010, 2012 and Devi and Maji 2011).Lai et al., (2006) indicated that Incorporation of ecological pesticide Artemisia arborescens essential oil into solid lipid nanoparticles reduced the rapid evaporation of essential oil, in comparison to the reference emulsions. The control efficacy of garlic essential oil loaded NPs against adult Tribolium casaneum remained over $80 \%$ after five months, due to the controlled slow release of the active components, in comparison to free garlic essential oil (11\%) (Yang et al., 2009). 


\section{International Journal of Science and Research (IJSR) \\ ISSN (Online) : 2319-7064}

Index Copernicus Value (2013) : 6.14 | Impact Factor (2014) : 5.611

In this work geranium oil Pelargonium graveolens (Geraniales: Geraniaceae) is incorporated into soild lipid nanoparticles to prepare nanoformulation, and chosen as carrier material for geranium essential oil. Solid lipid nanoparticles hold great promise for reaching the goal of controlled delivery system; they are lipid nanoparticles, which are attracting wide attention of formulators worldwide (Jumaa and Muller 2000). SLNs offer unique properties such as small size, large surface area, high drug (active ingredient) loading and are attractive for their potential to improve performance of pharmaceuticals, neutraceuticals and other materials (Bhattachary et al., 2010).

The aim of this study was to obtain and characterize polymeric nanoparticles containing essential oil (EO-NPs) and to evaluate some biological activities against the potato tuber larvae Phthorimaea operculella and compared with free EO, and to determine the direct effect and persistence of geranium oil pre/post nanoencapsulation in field-laboratory bioassay against $P h$. operculella, to lead to the discovery of new agents for pest control in the field and storage, it may be an effective alternative to conventional synthetic insecticides and encourage the use of these natural oils in nanoencapsulation and participate in programs of integrated pest management (IPM).

\section{Material and Methods}

\section{1) Insect Rearing}

A culture of Potato tuber moth, Phthorimaea operculella (Zeller) was maintained in the laboratory for several generations without exposure to insecticide, larvae reared mainly on the potato tubers in wooden cages $(35 \times 35 \times 45$ $\mathrm{cm}$ ). A thin layer of cleaned sand (exposed to high temperature in oven to kill other insects or parasitoids) was distributed on the bottom of the rearing cages to allow successful pupation and cocoon formation. Moths were supplied with a cotton-tuft moistened with $10 \%$ honey solution for feeding (El-Sinary, 1995). Culture and experiments were maintained at $29 \pm 1$ and $12 \mathrm{~L}: 12$ D photo period and $65 \pm 5 \%$ R.H.

\section{2) Materials}

Geranium essential oil extraction:

Stearic acid, tween-80, Soybean lecithin, dichloromethane.

\section{3) Bioassay Technique}

The newly hatched larvae were transferred by using fine brush and kept individually in glass jars and divided into three equal groups, the first one was fed on untreated fresh potato tubers and controlled daily to observe larval and pupal duration, pupal weight and adult longevity. The same criteria were observed and recorded in the case of the other two groups of the larvae, but by feeding on tubers of potato treated with selected concentrations of geranium essential oil 1.25 and $0.625 \%$ of geranium (above this range gave $100 \%$ mortality under laboratory conditions). Jars were covered with pieces of muslin cloth, twenty replicates were carried out for each treatment as well as for the control. The newly emerged moths sexed and transferred to glass jars provided with white cylindrical paper as an oviposition site, the top of the jars were covered with muslin cloth and fixed with rubber band. Moths fed on 10\% sugar solution; eggs fecundity and hatchability were recorded.

\subsection{Geranium essential oil (P. graveolens) - solid lipid nanoparticles (EO-SLNs) preparation}

Solid lipid nanoparticles were prepared using ultrasonicsolvent emulsification technique according to Sjostrom Bergenstahl 1992; Siekmann, 1996 and Asnawi et al., 2008. Two phases were prepared; oil phase and water phase.

Oil phase consists of $1 \%(\mathrm{w} / \mathrm{w})$ stearic acid which acts as lipid, and different concentrations $(5,2.5,1.25$ and $0.625 \%$ conc.) of geranium essential oil mixed with dichloromethane $(50 \mathrm{ml})$ and heated to $50{ }^{\circ} \mathrm{C}$.

Water phase consists of $2.5 \%(\mathrm{w} / \mathrm{w})$ Soybean lecithin and Tween- 80 which act as emulsifiers and dispersed in $50 \mathrm{ml}$ distilled water with magnetic stirring at the same temperature, a combination of emulsifiers helps to prevent particle agglomeration. After evaporating most of the solvents, the water phase was added to oil phase drop-bydrop at $50{ }^{\circ} \mathrm{C}$ followed by magnetic stirring for $10 \mathrm{~min}$.

The coarse emulsion was subjected to $55 \mathrm{~W}$ of ultrasonic treatment for $5 \mathrm{~min}$ using a high-power ultrasonication probe (Sonics Vibra Cell, Ningbo Haishu Kesheng Ultrasonic Equipments Co., Ltd, China) with water bath $\left(0{ }^{\circ} \mathrm{C}\right)$. The cold nanoemulsion then was dispersed into cold water using homogenizer (CAT Unidrive X1000 homogenizer), the cold water prevented lipid aggregation. This process followed by magnetic stirring to remove any traces of organic solvents. The oil- loaded SLNs suspension was filtered to remove the impurity materials and then stored at $4{ }^{\circ} \mathrm{C}$ for further bioassays.

\subsection{Geranium essential oil - solid lipid nanoparticles (EO-SLNs) characterization}

\section{(A) Determination of geranium essential oil loading efficiency}

The encapsulation efficiency (EE) and loading capacity (LC) of geranium-SLNs were determined as described by Tiyaboonchai et al., 2007 and Nayak et al., 2010. Ten milligrams of oil-loaded SLNs were accurately weighed and dissolved in $10 \mathrm{ml}$ of methanol. The samples were then centrifuged at 9, $000 \mathrm{rpm}$ for $30 \mathrm{~min}$. The amount of geranium oil in the supernatant was determined at $274 \mathrm{~nm}$ using UV-vis spectrophotometer (T80+ UV/VIS Spectrophotometer, PG instruments Ltd.). Oil concentration was calculated with the use of a calibration curve obtained from samples of pure geranium oil within a certain concentration range. Three replicates were prepared and measured for each oil concentration.

The encapsulation parameters were determined as follows:

$\mathrm{EE}=(\mathrm{A}-\mathrm{B}) / \mathrm{A} \times 100$
$\mathrm{LC}=(\mathrm{A}-\mathrm{B}) / \mathrm{C} \times 100$

Where;

A: the total amount of geranium oil $(5,2.5,1.25$ and $0.625 \%$ conc.) added to the formulation, 


\section{International Journal of Science and Research (IJSR) \\ ISSN (Online) : 2319-7064}

Index Copernicus Value (2013) : 6.14 | Impact Factor (2014) : 5.611

B: the amount of geranium oil measured in the supernatant, $\mathrm{C}$ : the total weight of lipid (stearic acid, 1\% w/w) in the formulation.

\section{(B) Transmission Electron Microscope}

Structural characterization and the morphology of geranium oil-SLNs were observed with JEOL JEM-2100 transmission electron microscopy (TEM). Samples were placed on carbon-coated TEM grids after a suitable dilution was created, then a drop of $2 \%$ phosphotungstic acid was added. The excess liquid was removed by blotting with a filter paper for $2 \mathrm{~min}$. The sample was allowed to dry for 10 minutes at room temperature before observation.

3.3 Biological activity of geranium essential oil after encapsulated SLNPs against $P h$. operculella under laboratory conditions

To determine the effect of geranium essential oil after it was encapsulated into SLNs on some biological parameters against $P h$. operculella larvae, suspensions of geraniumSLNs were used at 1.25 and $0.625 \%$ conc. Some biological parameters were determined such as larval duration, larval mortality, pupal duration and pupal mortality, also adult longevity and fecundity were recorded. Results obtained compared with those results obtained previously after treatment of geranium oil in its bulk size.

3.4 Field-laboratory bioassay to determine the efficiency and persistence of geranium essential oil pre/postnanoencapsulation against $P h$. operculella

The experiment of the field persistence study, was performed in filed potato crop located in El-Qanater ElKhayria, Qalyubia Governorate, Egypt during 2014/2015 winter season, when length of plant reached $25 \mathrm{~cm}$. Field area prepared for the experiment was $\left(15 \times 15 \mathrm{~m}^{2}\right)$ divided into labeled plots $(3 \times 3 \mathrm{~m}$ each), three plots for each treatment; 5, 2.5\% geranium oil-SLNs, 5, 2.5\% geranium oil and control, each plot contained four plants. For the treatment a pressure sprayer was used. Treatments were applied in the rate of $20 \mathrm{ml} / \mathrm{plot}$ and separated by untreated plants to prevent cross contamination. Three untreated plots were reserved as controls. After $2 \mathrm{~h}$ of application, leaves of every plot were collected randomly and put in paper bags then transferred to the laboratory for bioassay to determine the direct effects of the tested oil treatments. Newly hatched larvae of Ph. operculella were exposed to potato leaves from either treated or untreated control plots by the same procedure described above and the mortality was recorded for each treatment for $72 \mathrm{~h}$ under the same laboratory conditions to determine the direct effectiveness of oil pre/post-nanoencapsulation. Three replicates were used for each treatment; every replicate represents one of three treated plots. After one, three and five days (periods 1, 2 and 3 ) from the first treatment, potato leaves were collected and tested to evaluate the persistence/residual activity, and the mortality was recorded for each treatment.

Percentage of corrected mortality was calculated according to Abbott's formula:

Corrected $\%=\left(1-\frac{\mathrm{n} \text { in T after treatment }}{\mathrm{n} \text { in Co after treatment }}\right) * 100$
Where: $\mathbf{n}=$ Insect population in the sample, $\mathbf{T}=$ treated larvae, $\mathrm{Co}_{\mathbf{0}}=$ control larvae

\subsection{Statistical Analysis}

Data were analyzed using one way ANOVA. Significant differences between treatments were determined using Duncan's test $(P<0.05)$.

\section{Results and Discussion}

A- Geranium essential oil loaded with solid lipid nanoparticles and its characterization

Oil encapsulation efficiency (EE) is a critical factor for nanoparticles. A good nano carrier should have high oil encapsulation efficiency. The results show the encapsulation efficiency in the stearic acid as coating nanoparticles. It was positively correlated to the amount of geranium essential oil, that it is increased with the increasing of geranium oil concentration to stearic acid. Data obtained in table (1) show that the encapsulation efficiency for geranium oil nanoparticles significantly increased at the concentration 5\% was reached to $90.80 \pm 0.41$ accordingly the loading capacity (LC) became significant more being $4.54 \pm 0.02$, but when decreased the oil conc. to 1.25 and $0.625 \%$ the EE decreased to $85.60 \pm 0.92$ and $74.93 \pm 1.41$ and LC also decreased to $1.07 \pm 0.01$ and $0.46 \pm 0.09$ respectively for the two concentrations.

The morphology and characterization of geranium oil loaded solid lipid nanoparticles at different concentrations to stearic acid as coating material were visualized using transmission electron microscopy (TEM). Figures (1, 2, 3, and 4) show the particles appearing round, spherical in shape, a good dispersion and narrow size distribution, when geranium essential oil used at 5\% conc. the particle size seems to be larger (ranging 50-170 nm) (Fig., 1), at 2.5\% conc. of oil the size of particles ranged from $50-90 \mathrm{~nm}$ (Fig., 2) and it reduced to react to $30-80 \mathrm{~nm}$ and $24-70 \mathrm{~nm}$ for $1.25 \%$ and $0.625 \%$ conc. respectively (Fig., 3 and 4 ).

These results are in agreement with Yang et. al., (2009), they recorded that the oil-loading efficiency could reach $80 \%$ at the optimal ratio of garlic essential oil to $10 \%$ of polyethylene glycol (PEG) and proportion for other nano systems. Gonzalez et. al., (2014) detected that the sizes polydispersion index (PDI) and loading efficiency for eight essential oil-nanoparticles, the $10 \%$ ratio EO-PEG showed the best relationship between a low PDI (which measure the size of distribution of nanoparticles) and a high loading efficiency.

B- Biological activity of geranium essential oil (EO) and geranium essential oil loaded solid lipid nanoparticles (EO-SLNs) against the $1^{\text {st }}-4^{\text {th }}$ instar larvae of $\boldsymbol{P h}$. operculella

To determine the effect of the two concentrations (1.25 and $0.625 \%$ ) of the free geranium essential oil and compared to essential oil loaded solid lipid nanoparticles (EO-SLNs) on some biological aspects of $\mathrm{Ph}$. operculella larvae (from $1^{\text {st }}$ $4^{\text {th }}$ ) such as the larval duration, larval mortality, pupation and weight of the resulting pupae, adults longevity and female fertility. The data presented in table (2) show that 


\section{International Journal of Science and Research (IJSR) \\ ISSN (Online) : 2319-7064}

Index Copernicus Value (2013) : 6.14 | Impact Factor (2014) : 5.611

there was a significant prolongation $(\mathrm{P}<0.05)$ on the larval duration with the two concentrations ( 1.25 and $0.625 \%)$ of geranium essential oil pre and post loading and its efficacy was positively related to the concentration of the oil.

The larval duration after treatment with geranium oil at $1.25 \%$ conc. pre and post - loaded were $20.41 \pm 0.31$ and $23.62 \pm 0.46$ days respectively compared to the control larvae $(13.31 \pm 0.21$ days). The pupal duration had been significantly affected when the larvae fed on the potato tubers treated with geranium essential oil concentration $1.25 \%$ post-loaded as it showed a pronounced retardation (14.50 \pm 0.26 days) followed by the treatment with the same conc. of the oil pre-loaded ( $11.11 \pm 0.30$ days) compared with the control ( $7.22 \pm 0.19$ days). While the larval and pupal mortality increased with increasing the conc. of tested geranium oil in all treatments, the highest percentage of larval and pupal mortality occurred when the larvae treated with $1.25 \%$ conc. geranium oil loaded- SLNs (post loading) being 56 and $27.27 \%$ respectively compared with control larvae and pupae (5.00 and 5.26\%). Pupae that resulted from larvae treated with the two concs. (1.25 and $0.625 \%)$ of geranium essential oil loaded-SLNs showed a significant underweight pupae $(\mathrm{P}<0.05)(4.95 \pm 0.18$ and $5.95 \pm 0.11 \mathrm{mg})$ respectively compared with control pupae $(7.93 \pm 0.11 \mathrm{mg})$. On the other hand, just at $1.25 \%$ conc. significant differences were found in pupal weight between essential oil loaded- SLNs and essential oil alone (Table 2).

The post effect of the two concentrations of geranium essential oil pre/ post- loading on adult stage of $\mathrm{Ph}$. Operculella was evaluated in terms of adult longevity and female fecundity accordingly the percentage of hatchability. The data in table (2) show that there was a significant effect on the adults produced from the larvae treated with geranium essential oil loaded-SLNs with concs. (1.25 and $0.625 \%)$ had a short life span $(2.50 \pm 0.18$ and $3.15 \pm 0.19$ days respectively), significantly low fertility and the females moths that emerged failed to produce more eggs. The percentage of fecundity with respect to control became low (17.75\% and $33.52 \%$ respectively) and produced a notably decrease in offspring, the percentage of hatchability $(17.78 \%$ and $28.23 \%$ respectively) compared with untreated females $(85.79 \%)$.

The present investigation showed that the geranium essential oil (EO) free and loaded- SLNs at $1.25 \%$ conc. significantly affected on the developmental process of immature stages as well as increased the percentage of mortality, these results are in agreement with Yang et. al., (2009) who reported that, the control efficacy of nanoparticles containing garlic essential oil was superior to that of free garlic oil against the stored- product adults Tribolium castaneum and remained over $80 \%$ after five months, presumably due to the slow and persistence release of the active components from the nanoparticles. Nenaah (2014) tested essential oils of three Achillea sp. as nano-emulsions as fumigants, toxicity of oils were increased dramatically against the second instar larvae of $T$. castaneum. The developmental course, life span and F1 progeny of the pest were significantly affected. All of these developmental disruptions led to a great reduction in the number of adults that undergo successful emergence. While Gonzalez et. al., (2014) showed that in $T$. castaneum the
EO-NPs produced a notable increase of the residual contact toxicity apparently due to the slow and persistent release of the active terpenes. In addition, the nanoformulations exhibit unique properties compared with their bulk counterpart including a higher toxicity and were potent in its larvicidal effect against mosquito larvae Culex quinquefasciatus (Anjali et. al., 2010). The data obtained in the present work show that at the low conc. $0.625 \%$, the geranium essential oil loaded-SLNs was significant for the mortality of the larvae of $P h$. operculella reached nearly two times (44\%) more than the essential oil alone $(20 \%)$ but geranium EO loaded -SLNs at a higher conc. (1.25\%) determined the higher mortality $(56 \%) \quad(\mathrm{P}<0.05)$, hence possible postingestion toxicity was observed. It is known that nanoparticles oil have a much higher chemical activity than the bulk material much more mobile, enabling better penetration into insect tissues and enhancing insecticidal activity. This can be by direct contact through the insect's cuticle or by ingestion and penetration through the digestive tract (Margulis- Goshen and Magdassi, 2012). However, most of the insecticidal activities of plant oils are reported to be due to their content of monoterpenoides (Suthisut et. al., 2011).

\section{C- Direct effects and field persistence of geranium essential oil pre and post loaded solid lipid nanoparticles against $1^{\text {st }}$ larval instar of $\boldsymbol{P h}$. operculella.}

The direct effects and field persistence of geranium essential oil pre and post loading were investigated in the laboratory on the $1^{\text {st }}$ larval instar of Ph. operculella (Table 3). Spraying of tested oil at their field rates on leaves of the potato plants (in terms of time required for the death occurred). The results showed that a significant difference $(\mathrm{P}<0.5)$ between geranium oil loaded-SLNs (post loading) and the bulk form of the oil at the two concentrations ( 5 and $2.5 \%$ ). The oil post loaded exhibited more effective on the first instar larvae after $24 \mathrm{~h}$ of application which caused $100 \%$ death compared to $96.55 \%$ and $82.76 \%$ only of mortality with the free geranium essential oil at the same conc. and at the same time $(24 \mathrm{~h})$.

The residual effect of geranium oil (pre and post loading) was tested at intervals after field applications of one, three and five days. Results in table 3 indicated that the geranium oil loaded-SLNs at $5 \%$ conc. was more toxic for first larval instar as a direct and residual effect, the percentage of mean residual effect (period one, three and five days) of the oil loaded-SLNs was $90.21 \%$ compared with the free oil at the same concentration $(84.12 \%)$, while the concentration of geranium oil loaded-SLNs at $2.5 \%$ was less effective and the percentage of mean residual effect was $(82.89 \%)$ (Table 3$)$.

In this study, the comparative effects of geranium essential oil (EO) and EO-SLNs were determined to show their efficiency on this insect. The oil loaded-SLNs exhibited more efficiency on the first larval instar of the tested insect in laboratory bioassays in terms percentage of mortality and its stability. This data agrees with that of Abdel-Rahman et. al., (2007) when tested the direct and latent effects of some IGRs on the development of Spodoptera littoralis larvae, showed that the insect growth regulator Lufenuron has more toxic and delayed effects on the tested larval instars.

\section{Volume 4 Issue 11, November 2015}




\section{International Journal of Science and Research (IJSR) \\ ISSN (Online) : 2319-7064}

Index Copernicus Value (2013) : 6.14 | Impact Factor (2014) : 5.611

Studying the residual effects is needed to investigate the stability of the geranium oil (pre and post loading) under field conditions. The tested oil was more stable and more effective during intervals of this study. The total efficiency for field-laboratory experiments indicated that the EO-SLNs at concentrations 5 and $2.5 \%$ were more effective than the bulk form of the oil. This finding agrees with El-Sheikh and Aamir, (2011) who reported that, the field-laboratory experiments were conducted to show direct and residual effects of tested IGRs in terms of toxicity and stability, Lufenuron was more efficient and stable and give high percentage of mortality under field conditions against the second and fourth larval instar of $S$. littoralis.

Because the attention to natural bioinsecticides based on plant essential oils or their constituents is high for using them in pest control, they are testing under laboratory and field conditions on the different pests and beneficial insects to show their effectiveness and adverse effect as well. The tested essential oils nanopartricles appear to be promising candidates to control the major pests of plants, due to their high volatility and stability. Before implementing the use of such oils, large scale experiments are needed to evaluate their mammalian toxicity and to substantiate their efficacy under different conditions to validate their economic values as plant protectant.

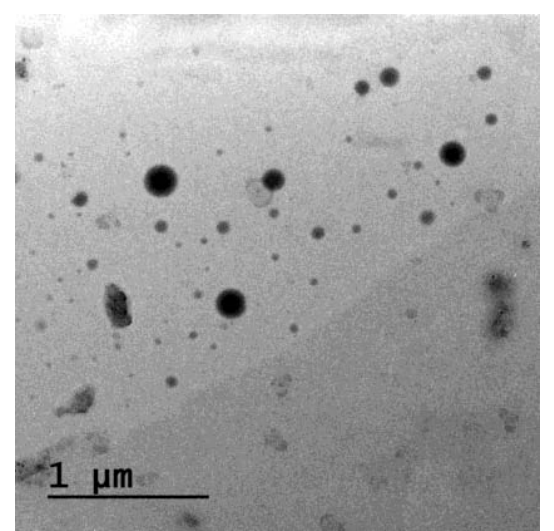

Figure 1: TEM of geranium essential oil SLNs at 5\%

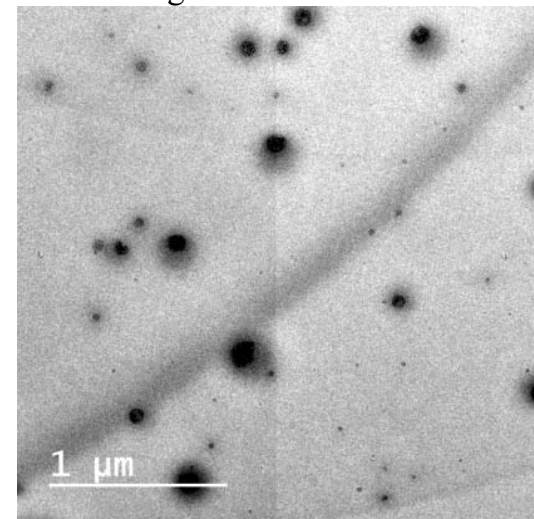

Figure 2: TEM of geranium essential oil SLNs at 2.5\%

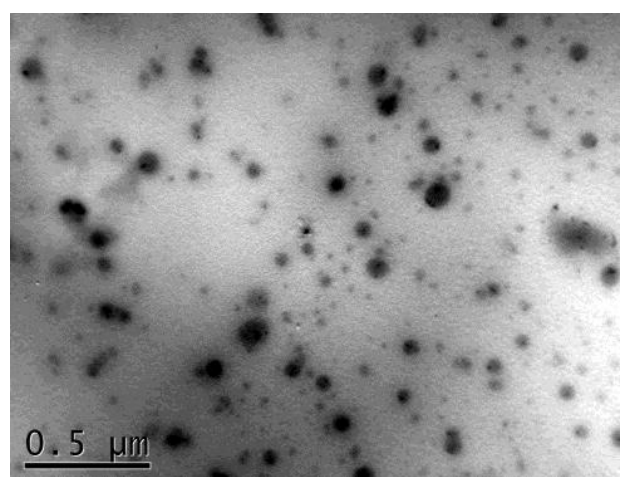

Figure 3: TEM of geranium essential oil SLNs at $1.25 \%$ conc.

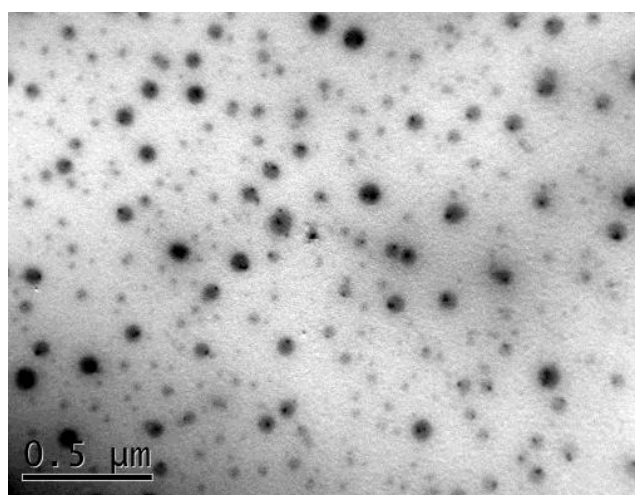

Figure 4: TEM of geranium essential oil SLNs at $0.625 \%$ conc.

Table 1: Effect of geranium oil concentration on the encapsulation efficiency and loading capacity of geraniumloaded SLNs

\begin{tabular}{|c|c|c|}
\hline $\begin{array}{c}\text { Concentration } \\
\text { of Geranium } \\
\text { oil }\end{array}$ & $\begin{array}{c}\text { \% Encapsulation } \\
\text { efficiency }(E E) \\
(M \pm S E)\end{array}$ & $\begin{array}{c}\text { \% Loading } \\
\text { capacity }(L C) \\
(M \pm S E)\end{array}$ \\
\hline $5 \%$ & $90.80 \pm 0.41 \mathrm{a}$ & $4.54 \pm 0.02 \mathrm{a}$ \\
\hline $2.5 \%$ & $93.46 \pm 0.35 \mathrm{a}$ & $2.33 \pm 0.09 \mathrm{~b}$ \\
\hline $1.25 \%$ & $85.60 \pm 0.92 \mathrm{~b}$ & $1.07 \pm 0.01 \mathrm{c}$ \\
\hline 0.625 & $74.93 \pm 1.41 \mathrm{c}$ & $0.46 \pm 0.09 \mathrm{~d}$ \\
\hline F-Value & $85.52^{* *}$ & $17998.45^{* *}$ \\
\hline
\end{tabular}

Mean (M. \pm S.E) values with different letters within the same row are significantly different $(\mathrm{P}<0.05)$ (ANOVA) (Duncan test)

$* *=$ Highly significant

$\mathrm{EE}=(\mathrm{A}-\mathrm{B}) / \mathrm{A} X 100$

$\mathrm{LC}=(\mathrm{A}-\mathrm{B}) / \mathrm{C}$ X 100 


\section{International Journal of Science and Research (IJSR) \\ ISSN (Online) : 2319-7064}

Index Copernicus Value (2013) : 6.14 | Impact Factor (2014) : 5.611

Table 2: Effect of geranium essential oil pre/post- loaded SLNs on some biological aspects of $1^{\text {st }}$ larval instar of $P h$. operculella

\begin{tabular}{|c|c|c|c|c|c|c|c|c|c|}
\hline $\begin{array}{l}\text { Plant oil } \\
\text { conc. } \\
\text { pre/post- } \\
\text { loading } \\
\text { SLNs }\end{array}$ & $\begin{array}{c}\text { Larval } \\
\text { Duration / } \\
\text { days }\left(1^{s t}-4^{\text {th }}\right)\end{array}$ & $\begin{array}{l}\% \text { Larval } \\
\text { mortality }\end{array}$ & $\begin{array}{c}\text { Pupal } \\
\text { duration / } \\
\text { days }\end{array}$ & $\begin{array}{l}\text { Pupal wt./ } \\
\text { mg }\end{array}$ & $\begin{array}{c}\% \text { Pupal } \\
\text { mortality }\end{array}$ & $\begin{array}{c}\text { Adult } \\
\text { longevity / } \\
\text { days }\end{array}$ & $\begin{array}{l}\text { No. eggs } \\
\text { /female }\end{array}$ & $\begin{array}{c}\% \text { fecundity } \\
\text { with respect } \\
\text { to control }\end{array}$ & $\begin{array}{c}\% \\
\text { hatchability }\end{array}$ \\
\hline $\begin{array}{l}1.25 \% \\
\text { conc. }\end{array}$ & $20.41 \pm 0.31 \mathrm{~b}$ & $40 \%$ & $11.11 \pm 0.30 \mathrm{c}$ & $6.19 \pm 0.27 \mathrm{c}$ & $8.33 \%$ & $3.44 \pm 0.24 \mathrm{c}$ & $22.66 \pm 1.45 \mathrm{c}$ & $26.81 \%$ & $26 \%$ \\
\hline $\begin{array}{c}0.625 \% \\
\text { con. }\end{array}$ & $16.05 \pm 0.18 \mathrm{~d}$ & $20 \%$ & $9.25 \pm 0.21 \mathrm{~d}$ & $6.84 \pm 0.14 \mathrm{~b}$ & $12.5 \%$ & $4.85 \pm 0.17 \mathrm{~b}$ & $34.66 \pm 2.02 \mathrm{~b}$ & $41.01 \%$ & $52.88 \%$ \\
\hline $\begin{array}{l}1.25 \% \\
\text { conc. } \\
\text { loaded } \\
\text { SLNs } \\
\end{array}$ & $23.62 \pm 0.46 \mathrm{a}$ & $56 \%$ & $14.50 \pm 0.26 \mathrm{a}$ & $4.95 \pm 0.18 \mathrm{~d}$ & $27.27 \%$ & $2.50 \pm 0.18 \mathrm{~d}$ & $15.00 \pm 2.88 \mathrm{~d}$ & $17.75 \%$ & $17.78 \%$ \\
\hline $\begin{array}{c}0.625 \% \\
\text { conc. } \\
\text { loaded } \\
\text { SLNs } \\
\end{array}$ & $17.69 \pm 0.20 \mathrm{c}$ & $44 \%$ & $13.38 \pm 0.24 \mathrm{~b}$ & $5.95 \pm 0.11 \mathrm{c}$ & $7.14 \%$ & $3.15 \pm 0.19 \mathrm{c}$ & $28.33 \pm 2.02 b c$ & $33.52 \%$ & $28.23 \%$ \\
\hline Control & $13.31 \pm 0.21 \mathrm{e}$ & $5 \%$ & $7.22 \pm 0.19 \mathrm{e}$ & $7.93 \pm 0.11 \mathrm{a}$ & $5.26 \%$ & $8.88 \pm 0.17 \mathrm{a}$ & $84.50 \pm 1.65 \mathrm{a}$ & - & $85.79 \%$ \\
\hline F-Value & $212.85 * *$ & - & $160.43 * *$ & $50.88 * *$ & - & $201.21 * *$ & $212.24 * *$ & - & - \\
\hline
\end{tabular}

Mean (M. \pm S.E) values with different letters within the same row are significantly different $(\mathrm{P}<0.05)$ (ANOVA) (Duncan test) $* *=$ Highly significant

Table 3: The direct effects and field persistence of geranium essential oil pre/post- loaded SLNs against Ph. operculella first instar larvae

\begin{tabular}{|c|c|c|c|c|c|}
\hline \multirow[b]{3}{*}{$\begin{array}{l}\text { Plant oil conc } \\
\text { pre/post- } \\
\text { loading SLNs }\end{array}$} & \multicolumn{5}{|c|}{$\%$ Corrected mortality $^{a}$} \\
\hline & \multirow[b]{2}{*}{$\begin{array}{l}\% \text { Direct } \\
\text { Effect }^{b}\end{array}$} & \multicolumn{3}{|c|}{ Residual effect after ${ }^{c}$} & \multirow[b]{2}{*}{$\begin{array}{l}\% \text { Mean } \\
\text { residual } \\
\text { effect }\end{array}$} \\
\hline & & $\mid \begin{array}{l}\text { Period } 1 \\
\text { (one day) }\end{array}$ & $\begin{array}{c}\text { Period } 2 \\
\text { (three } \\
\text { days) }\end{array}$ & $\begin{array}{c}\text { Period } 3 \\
\text { (five } \\
\text { days) }\end{array}$ & \\
\hline $5 \%$ & 96.55 & 92.59 & 85.71 & 74.07 & 84.12 \\
\hline $5 \%$ Oil-SLNs & 100 & 96.3 & 92.86 & 81.48 & 90.21 \\
\hline $2.5 \%$ conc. & 82.76 & 77.78 & 64.29 & 37.04 & 59.70 \\
\hline $2.5 \%$ Oil-SLN & 100 & 88.89 & 85.71 & 74.07 & 82.89 \\
\hline
\end{tabular}

apercentage of corrected mortality was calculated according to Abbott's formula

${ }^{\mathrm{b}}$ Direct effect means that bioassay was started $\sim 2 \mathrm{~h}$ after field application with geranium essential oil pre/post loaded SLNs.

${ }^{\mathrm{c}}$ Residual effect was estimated in field-lab bioassay. Periods 1,2 and 3 mean that bioassay was started after 1, 3 and 5 days, respectively from original field treatment with geranium essential oil pre/post- loaded SLNs.

\section{References}

[1] Abbott, W. (1925).A method for computing the effectiveness of an insecticide. J. Econ. Entomol., 18, 265-267.

[2] Abd El-Aziz, M. F. (2011). Bioactivities and Biochemical Effects of Marjoram Essential Oil used against Potato Tuber Moth Phthorimaea operculella Zeller (Lepidoptera: Gelechiidae). Life Science Journal; 8 (1), 288-297.

[3] Abdel Rahman, S. M., Hegazy, E. M., Elwey, A. E. (2007). Direct and latent effects of two chitin synthesis inhibitors to Spodoptera littoralis larvae (Boisd). American- Eurasian J. Agric. Environ. Sci. 2 (4), 457464.
[4] Al-Dhafer, Z. M. A. (2001). Studies on the effect of natural products of some Saudi Arabian plants on the biology and behavior of the American bollworm Helicovirpa armigera (Hubn.) (Lepidoptera: Noctoidae). M.Sc. Thesis, Fac. Sci; Girls College, Dammam, Saudi Arabia.

[5] Al-Dosary, M. M. (2007). Sensory receptors and behaviour of the Red Palm Weevil Rhynchophorus ferrugineus (Oliv.) (Colioptera: Curculionidae) with reference to attractants, repellents and control. Ph.D. Thesis. Riyadh Girls College of Education Scientific Section, Department of Zoology, p. 269.

[6] Anjali, C. H., Khan, S. S., Margulis-Goshen, K., Magdassi, S., Mukherjee, A., Chandrasekaran, N. (2010). Formulation of water-dispersible nanopermethrin for larvicida applications. Ecotox. Environ. Safe. 73, 1932-1936.

[7] Anjali, C. H., Sharma, Y., Mukherjee, A., Chandrasekaran, N. (2012). Neem oil (Azadirachta indica) nanoemulsion - a potent larvicidal agent against Culex quinquefasciatus Pest. Manage. Sci. 68, 158-163.

[8] Asnawi, S., Abd. Aziz, A., R.Khamis, A. K. (2008). Formulation of geranium oil loaded solid lipid nanoparticles for mosquito repellent application. Jor Journal of Chemical and Natural Resources Engineering. 2, 90-99.

[9] Bhattacharyya, A., Bhaumik, A., Usha Rani, P., Mandal, S. and Epidi, T. T. (2010). Nano-particles - A recent approach to insect pest Control. African Journal of Biotechnology Vol. 9 (24), 3489-3493.

[10] Burfield, T., Reekie, S. L. (2005).Mosquitoes, malaria and essential oils. Int. J. Aromatherapy 15, 30-41.

[11]El-Sheikh, E. A. and Aamir, M. M. (2011).Comparative effectiveness and field persistence of insect growth regulators on a field strain of the cotton leafworm, Spodoptera littoralis, Boisd (Lepidoptera: Noctuidae). Crop Protection, 30, 645-650.

[12]El-Sinary, N.H. (1995). Magnitude and applicability of gamma-irradiation and controlling atmospheres to

\section{Volume 4 Issue 11, November 2015}




\section{International Journal of Science and Research (IJSR) \\ ISSN (Online) : 2319-7064}

Index Copernicus Value (2013) : 6.14 | Impact Factor (2014) : 5.611

minimize the hazards to potato tubermoth, Phthorimaea operculella (Zeller). Ph. D. thesis Fac. Agric. Cairo Univ., Egypt, pp: 187.

[13] Ghormade, V., Deshpande, M. V. and Paknicar, K. M. (2011). Perspectives for nano biotechnology enabled protection and nutrition of plants. Biotechnol. Adv. 29, 792-803.

[14] Gomah E. Nenaah. (2014). Chemical composition, toxicity and growth inhibitory activities of essential oils of three Achilleaspecies and their nano-emulsions against Tribolium castaneum (Herbst).Industrial Crops and Products, 53. 252- 260.

[15] Jumaa, M., Muller, B. W. (2000). Lipid emulsions as a novel system to reduce the hemolytic activity of lytic agents: mechanism of protective effect. Eur J Pharm Sci., 9 (3), 285-90.

[16] Kroschel, J. andKoch, W. (1996).Studies on the use of chemicals, botanicals and Bacillus thuringiensis in the management of the potato tuber moth in potato stores. Volume 15 (2), 197-203.

[17]Lai, F., Sylvia A. W., Rainer H. M. and Anna M. F. (2006).Artemisia arborescens L Essential Oil-Loaded Solid Lipid Nanoparticles for Potential Agricultural Application: Preparation and Characterization. AAPS PharmSciTech., 7 (1), E10-E18.

[18]Lee, B. H., Annis, P. C., Tumaalii, F., Choi, W. (2004). Fumigant toxicity of essential oils from Myrtaceae family and 1, 8-cineol against 3 major stord - grain insects. J. Stord. Products 40, 553-564.

[19] Llanderal-Cazares, C., A. Lagunes-Tejada, J. L. Carrillo-Sanchez, C. Sosa-Moss, J. Vera-Graziano, and H. Bravo-ojica. (1996). Susceptibility of Phthorimaea operculella (Zeller) to insecticides. J. Entomol. Sci. 31:420-426.

[20] Margulis-Goshen, K., Magdassi, S. (2012). Nanotechnology: an advanced approach to the development of potent insecticides. In: Ishaaya, I., Reddy, P.S., Rami, H.A. (Eds.), Advanced Technologies for Managing Insect Pests. Springer Science and Business Media, New York, pp. 295-314.

[21] Nayak, A. P., Tiyaboonchai, W., Patankar, S., Madhusudhan, B., Souto, E. B. (2010).Curcuminoidsloaded lipid nanoparticles: novel approach towards malaria treatment. Colloids Surf B Biointerfaces. 1;81 (1), 263-73.

[22] Nirmala Devi and Tarun K. Maji (2011).Neem Seed Oil: Encapsulation and Controlled Release - Search for a Greener Alternative for Pest Control, Pesticides in the Modern World - Pesticides Use and Management, Dr. Margarita Stoytcheva (Ed.), ISBN: 978-953-307-459-7, InTech, DOI: 10.5772/17590. Available from: http://www.intechopen.com/books/pesticides-in-themodern-world-pesticides-use-and-management/neemseed-oil-encapsulation-and-controlled-release-searchfor-a-greener-alternative-for-pest-control

[23] Rama, H. N. (1989). Studies on the toxic effects of plant seed oils against the potato tuber moth. Phthorimae operculella Zell. (Lepidoptcra: Gclcchiidac). Mysorr J. Agric. Sri. 23, 568-560.

[24] Regnault-Roger C., Vincent C., Arnason J. T. (2012). Essential oils in insect control: low-risk products in a high-stakes world. Annu. Rev. Entomol. 57, 405-24.
[25] Sharaby, A., Abdel-Rahman, H., Moawad, S. (2009). Biological effects of some natural and chemical compounds on the potato tuber moth, Phthorimaea operculella Zell. (Lepidoptera: Gelechiidae). Saudi Journal of Biological Sciences 16, 1-9.

[26] Siddig, S. A. (1986). A proposed pest management program including neem treatments for combating potato pests in Sudan. Proc. ThirdInt. Neem Conf., Nairobi, Kenya, pp. 449-459.

[27] Siekmann, B., Westesen, K. (1996). Investigations on solid lipid nanoparticles prepared by precipitation in o/w emulsions. Eur J Pharm Biopharm 43, 104-109.

[28] Sjostrom B, Bergenståhl B. (1992). Preparation of submicron drug particles in lecithin-stabilized $\mathrm{o} / \mathrm{w}$ emulsions I. Model studies of the precipitation of cholesterylacetate. Int J Pharm., 88, 53-62.

[29] Suthisut, D., Fields, P., Chandrapatya, A. (2011). Fumigant toxicity of three essential oils from three Thai plants (Zingiberaceae) and their major compounds against Sitophilus zeamais, Tribolium castaneum and two parasitoids. J. Stored Prod. Res. 47, 222-230.

[30] Tiyaboonchai, W., Tungpradit, W., Plianbangchang, P. (2007). Formulation and characterization of curcuminoids loaded solid lipid nanoparticles, Int. J. Pharm. 337, 299-306.

[31] Werdin González, J. O., Gutiérrez, M. M., Ferrero, A. A., Fernández Band, B. (2014). Essential oils nanoformulations for stored-product pest control characterization and biological properties. Chemosphere, 100, 130-138.

[32] Yang, F. L., Li, X. G., Zhu, F. and Lei, C. L. (2009). Structural Characterization of Nanoparticles Loaded with Garlic Essential Oil and Their Insecticidal Activity against Tribolium castaneum (Herbst) (Coleoptera: Tenebrionidae). J. Agric. Food Chem., 57, 1015610162. 